\title{
Effect of Low-Dose Aspirin on Soluble FMS-Like Tyrosine Kinase 1/Placental Growth Factor (sFlt-1/PIGF Ratio) in Pregnancies at High Risk for the Development of Preeclampsia
}

\author{
Karoline Mayer-Pickel ${ }^{1, *,+} \mathbb{D}$, Vassiliki Kolovetsiou-Kreiner ${ }^{1,+}$, Christina Stern ${ }^{1}$, \\ Julia Münzker ${ }^{2}$, Katharina Eberhard ${ }^{3}$, Slave Trajanoski ${ }^{3}$, Ioana-Claudia Lakovschek ${ }^{1} \mathbb{D}$, \\ Daniela Ulrich ${ }^{1}{ }^{(D}$, Bence Csapo ${ }^{1}$, Uwe Lang ${ }^{1}$, Barbara Obermayer-Pietsch ${ }^{2}$ and \\ Mila Cervar-Zivkovic ${ }^{1}$ \\ 1 Department of Obstetrics and Gynecology, Division of Obstetrics, Medical University of Graz, \\ A-8036 Graz, Austria \\ 2 Department of Internal Medicine, Div. of Endocrinology and Diabetology, Endocrinology Lab Platform, \\ Medical University of Graz, A-8036 Graz, Austria \\ 3 Department for Core Facility Computational Bioanalytics, Center for Medical Research (ZMF), \\ Medical University of Graz, A-8036 Graz, Austria \\ * Correspondence: karoline.pickel@medunigraz.at \\ + Both authors equally contributed.
}

Received: 8 August 2019; Accepted: 3 September 2019; Published: 10 September 2019

\begin{abstract}
Background: Soluble FMS-like Tyrosine Kinase 1 (sFlt-1) and placental growth factor (PIGF) have been reported to be highly predictive several weeks before the onset of preeclampsia. Objective: To investigate longitudinal changes of serum levels sFlt- 1 and PIGF in pregnant women at high risk for the development of preeclampsia and to reveal an impact of aspirin on maternal serum concentrations of sFlt- 1 and PlGF. Methods: This was a prospective longitudinal study in 394 women with various risk factors for the development of preeclampsia (chronic hypertension, antiphospholipid syndrome/APS or systemic lupus erythematosus/SLE, thrombophilia, women with a history of preeclampsia, pathologic first trimester screening for preeclampsia) and 68 healthy women. Serum levels of sFlt- 1 and PlGF were measured prospectively at 4-week intervals (from gestational weeks 12 until postpartum). Results: The sFlt-1/PlGF ratio was significantly higher in women with an adverse obstetric outcome compared to women with a normal pregnancy, starting between 20 and 24 weeks of gestation. There was no effect of aspirin on sFlt-1/PIGF ratio in women with chronic hypertension, APS/SLE, thrombophilia and controls. The use of aspirin showed a trend towards an improvement of the sFlt-1/PIGF ratio in women with preeclampsia in a previous pregnancy and a significant effect on the sFlt-1/PIGF ratio in women with a pathologic first trimester screening for preeclampsia. Conclusions: Our findings reveal an impact of aspirin on sFlt-1/PIGF ratio in women with a pathologic first trimester screening for preeclampsia, strongly supporting its prophylactic use.
\end{abstract}

Keywords: adverse pregnancy outcome; aspirin; first trimester screening for preeclampsia; high-risk pregnancies; preeclampsia; sFlt1/PlGF ratio

\section{Introduction}

Preeclampsia is a pregnancy-specific multiorgan disorder, complicating $3-5 \%$ of all pregnancies [1,2]. Despite advances in fetomaternal management, preeclampsia is still a major cause of maternal and neonatal morbidity and mortality worldwide, especially in developing countries. It is 
a known fact that the prevalence of preeclampsia is $3-5$ times higher in women with preeclampsia in a previous pregnancy as well as in women with chronic hypertension $[3,4]$. Furthermore, pregnancies in women with certain autoimmune diseases such as systemic lupus erythematosus (SLE) or antiphospholipid syndrome (APS) are complicated by preeclampsia in up to $8-35 \%$ [5-10]. An association of maternal thrombophilia and preeclampsia has been reported, although with conflicting results $[11,12]$. Preeclampsia is not a single disease, but rather a syndrome, affecting many organs and is characterized by endothelial dysfunction. Although the exact mechanisms are still unknown, several systemic processes have been proposed and are well accepted: Angiogenic imbalance, oxidative stress, and exaggerated systemic inflammation [13-16]. Daily administration of low-dose aspirin (LDA) has a modest beneficial effect in reducing the rate of preterm preeclampsia [17-22]. It has been demonstrated that the use of LDA from 11 to 14 weeks of gestation until 36 weeks of gestation reduces the incidence of early onset preeclampsia by approximately $60 \%$ [21]. According to several previous studies, aspirin improves implantation and placentation and has vasodilatory effects by increasing prostacyclin production. Aspirin seems to have a direct effect on platelets and might improve endothelial dysfunction [23].

The effect of aspirin on angiogenic factors, such as soluble FMS-like Tyrosine Kinase 1 (sFlt-1) and placental growth factor (PIGF) is the subject of ongoing interest and has been examined in several in vitro studies.

The aim of the present study was to evaluate the serum levels of sFlt- 1 and PIGF in women at high risk for the development of preeclampsia longitudinally during pregnancy and to determine a potential impact of LDA on the maternal serum concentrations of these angiogenic markers.

\section{Patients and Methods}

A total of 394 women were included in this prospective cohort study. Inclusion criteria were singleton pregnancies with one or more of the following risk factors for the development of preeclampsia: Chronic hypertension, SLE and/or APS, maternal thrombophilia, history of preeclampsia, and a pathologic first trimester screening for preeclampsia. Controls were women without any known predisposing risk factors for the development of preeclampsia.

Exclusion criteria were fetal abnormalities, fetal loss before $23+0$ weeks of gestation, and multiple pregnancies.

Women were recruited at time of admission for prenatal care, starting between 10 and 12 weeks of gestation.

Women with APS fulfilled at least one of the Sydney clinical criteria [24] and women with SLE showed at least 4 of the 11 American College of Rheumatology (ACR) criteria [25]. Apart from APS, maternal thrombophilia was defined as an inherited or acquired condition which predisposes an individual to thromboembolism, such as antithrombin deficiency, APC resistance, Factor V Leiden mutation, Factor II G202IOA, or combined effects [12].

Chronic hypertension, preeclampsia, and HELLP (hemolysis elevated liver enzymes low platelets) syndrome were defined according to international criteria [26]. IUGR (intrauterine growth restriction) was defined as fetal growth $<5$ th percentile of gestational age.

The first trimester screening for preeclampsia consisted of a combination of maternal demographic characteristics, including medical and obstetric history, uterine artery pulsatility index (PI), mean arterial pressure (MAP) and maternal serum pregnancy-associated plasma protein-A (PAPP-A), and placental growth factor (PlGF) at 11-13 weeks gestation [27].

Blood samples were collected without anticoagulant every 4 weeks from time of study inclusion until delivery. Samples were centrifuged at $800 \times g$ for $10 \mathrm{~min}$; sera were portioned in $200 \mu \mathrm{L}$ aliquots and stored at the Biobank Graz, Austria, at $-80^{\circ} \mathrm{C}$.

sFlt-1 and PIGF were measured using an automated ELISA (Roche Diagnostics GmbH; Mannheim, Germany) according to the manufacturer's protocol. The detection limit was $6 \mathrm{pg} / \mathrm{mL}$ for sFlt- 1 and $<2 \mathrm{pg} / \mathrm{mL}$ for PIGF. The intra-assay coefficients of variation were $<2 \%$ for sFlt- 1 and PlGF, and the 
inter-assay coefficients of variation were $2.3 \%$ to $4.3 \%$ for the sFlt- 1 assay and $2.7 \%$ to $4.1 \%$ for the PlGF assay.

The study protocol was approved by the Medical University Ethics Committee (IRB00002556) and all participants gave written informed consent.

\section{Statistical Analysis}

After data closure, all variables passed a plausibility check to detect outliers in the data set. No extreme values have been extracted from the full data set. Assumption of normal distribution was proven with Shapiro-Wilk and Kolmogorov-Smirnov tests ( $p>0.05$ normally distributed data assumed) and Q-Q plots. Comparisons among different outcome groups were tested with Mann-Whitney $\mathrm{U}$ and Kruskal-Wallis tests with post-hoc Bonferroni correction for multiple testing. To investigate longitudinal changes over time on different outcome variables and to deal with random effects and unequal sample sizes for the different gestational age weeks (measured for sFlt-1/PIGF-ratio) linear mixed effects models were performed. The linear mixed effects models were performed as restricted maximum likelihood (REML) approach combined with the Satterthwaite's method. The patient ID of pregnant women was considered as a person-specific random effect. In the intervals for different stages of gestational age, when more than one sample existed per woman, the latest sample was used.

Data are presented as total number, as mean \pm standard deviation, or in case of a skewed distribution, as median and interquartile range (25-percentile and 75-percentile). A two-tailed $p$-value of less than $p<0.05$ was considered as statistically significant. All statistical tests were performed using SPSS version 25.0 (SPSS Inc., Chicago, IL, USA), R version 3.4.1 (package lmer), and GraphPad Prism version 6.05 (GraphPad Software, San Diego, USA) for visualizations.

\section{Results}

The study group consisted of 89 women with chronic hypertension, 44 women with SLE and/or APS, 22 women with thrombophilia, 118 women with a history of preeclampsia, 53 women with a pathologic first trimester screening for preeclampsia, and 68 controls.

Maternal thrombophilia—apart from APS—consisted in most cases of APC resistance, Faktor V Leiden mutation.

Overall, first trimester screening for preeclampsia has been performed in 243 women; 113 women were screened positive for either early or late onset preeclampsia.

Demographic and clinical characteristics are shown in Table 1.

Women with chronic hypertension had a significantly higher prepregnancy BMI and a higher systolic and diastolic blood pressure at study entry (Table 1).

There were no significant differences in maternal age, prepregnancy BMI, and systolic and diastolic blood pressure at study entry between women with APS/SLE, maternal thrombophilia, preeclampsia in a previous pregnancy, pathologic first trimester screening for preeclampsia, and controls (Table 1).

Early onset preeclampsia occurred in three women with chronic hypertension, in two women with APS/SLE, in one woman with thrombophilia (APC-resistance), and in seven women with preeclampsia in a previous pregnancy, with HELLP syndrome complicating two of them. One woman with a pathologic first trimester screening for preeclampsia developed early onset preeclampsia and one woman of the control group.

Late onset preeclampsia occurred in thirteen women with chronic hypertension, in six women with APS/SLE, and in seven women with preeclampsia in a previous pregnancy. Six women with a pathologic first trimester screening for preeclampsia developed late onset preeclampsia and three women of the control group.

IUGR was present in ten pregnancies; two in women with chronic hypertension, preeclampsia in a previous pregnancy, and in controls, respectively, as well as in four women with APS/SLE. 
Table 1. Demographic characteristics of women included in the study.

\begin{tabular}{|c|c|c|c|c|c|c|c|}
\hline & $\begin{array}{c}\text { Chronic } \\
\text { Hypertension } \\
(\mathrm{n}=89)\end{array}$ & $\begin{array}{l}\text { APS/SLE } \\
(\mathrm{n}=44)\end{array}$ & $\begin{array}{l}\text { Thrombophilia } \\
\quad(n=22)\end{array}$ & $\begin{array}{l}\text { History of } \\
\text { Preeclampsia } \\
(n=118)\end{array}$ & $\begin{array}{c}\text { Pathologic First } \\
\text { Trimester } \\
\text { Screening }(n=53)\end{array}$ & $\begin{array}{l}\text { Controls } \\
(n=68)\end{array}$ & $\mathbf{P}$ \\
\hline $\begin{array}{c}\text { Maternal age } \\
\text { (years) }\end{array}$ & $33.4 \pm 5.8$ & $32.4 \pm 6.2$ & $29.45 \pm 5.9$ & $32.9 \pm 4.5$ & $33.9 \pm 4.8$ & $34.1 \pm 6$ & n.s. \\
\hline $\begin{array}{c}\text { Prepregnancy BMI } \\
\left(\mathrm{kg} / \mathrm{m}^{2}\right)\end{array}$ & $31.02 \pm 7.4$ & $23.9 \pm 4.5$ & $26.4 \pm 6.7$ & $25.5 \pm 5.6$ & $25.5 \pm 6.5$ & $26.5 \pm 6.7$ & 0.001 \\
\hline $\begin{array}{l}\text { Average systolic } \\
\text { blood pressure } \\
(\mathrm{mm} \mathrm{Hg})\end{array}$ & $143.8 \pm 19.2$ & $\begin{array}{c}132.6 \pm \\
11.2\end{array}$ & $129.8 \pm 16.2$ & $135.8 \pm 12.8$ & $131.2 \pm 13.2$ & $\begin{array}{c}128.9 \pm \\
15.1\end{array}$ & 0.001 \\
\hline $\begin{array}{c}\text { Average diastolic } \\
\text { blood pressure } \\
(\mathrm{mm} \mathrm{Hg})\end{array}$ & $93.1 \pm 13.1$ & $84.2 \pm 8.2$ & $85.5 \pm 15.9$ & $91.5 \pm 12.8$ & $89.5 \pm 10.8$ & $79.1 \pm 11.7$ & 0.001 \\
\hline \multicolumn{8}{|l|}{ Ethnicity } \\
\hline African, no. (\%) & $2(2.2 \%)$ & $1(2.2 \%)$ & 0 & 0 & 0 & 0 & \\
\hline Arabian, no. (\%) & $2(2.2 \%)$ & $2(4.5 \%)$ & 0 & $4(3.4 \%)$ & 0 & 0 & \\
\hline Asian, no. (\%) & 0 & 0 & 0 & $1(0.8 \%)$ & 0 & 0 & \\
\hline $\begin{array}{l}\text { Caucasian, no. (\%) } \\
\text { low dose aspirin }\end{array}$ & $85(95.5 \%)$ & $41(93.3 \%)$ & $22(100 \%)$ & $113(95.8 \%)$ & $53(100 \%)$ & 68 & \\
\hline Overall, no. (\%) & $70(78.6 \%)$ & $40(90.9 \%)$ & $10(45.5 \%)$ & $110(93.2 \%)$ & $51(96.2 \%)$ & 0 & \\
\hline$<100 \mathrm{mg}$, no. $(\%)$ & $18(20.2 \%)$ & $4(9.1 \%)$ & $1(4.5 \%)$ & $13(11 \%)$ & $7(13.2 \%)$ & 0 & \\
\hline $100 \mathrm{mg}$, no. $(\%)$ & $26(29.2 \%)$ & $23(52.2 \%)$ & $5(22.7 \%)$ & $60(50.8 \%)$ & $29(54.7 \%)$ & 0 & \\
\hline 150 mg, no. (\%) & $26(29.2 \%)$ & $13(29.5 \%)$ & $4(18.2 \%)$ & 37 (31.45) & $15(12.7 \%)$ & 0 & \\
\hline preeclampsia & $16(17.9 \%)$ & $8(18.2 \%)$ & $1(4.5 \%)$ & 19 (16.15) & $6(11.3 \%)$ & $4(5.9 \%)$ & \\
\hline $\begin{array}{c}\text { Gestational age at } \\
\text { delivery }\end{array}$ & $38.9 \pm 1.1$ & $37.8 \pm 3$ & $39.1 \pm 3.3$ & $38.8 \pm 2$ & $40.1 \pm 1.1$ & $39.5 \pm 1.8$ & n.s. \\
\hline \multicolumn{8}{|l|}{ Mode of delivery } \\
\hline $\begin{array}{c}\text { Spontaneous } \\
\text { delivery, no. (\%) }\end{array}$ & $30(33.7 \%)$ & $12(27.3 \%)$ & $10(45.5 \%)$ & $48(40.7 \%)$ & $23(43.4 \%)$ & $36(52.9 \%)$ & \\
\hline $\begin{array}{c}\text { caesarean section, } \\
\text { no. }(\%)\end{array}$ & $56(62.9 \%)$ & $28(63.6 \%)$ & $11(50 \%)$ & $69(58.5 \%)$ & $23(43.4 \%)$ & $28(41.2 \%)$ & \\
\hline $\begin{array}{l}\text { vaginal assisted } \\
\text { delivery, no. }(\%)\end{array}$ & $3(3.4 \%)$ & $4(9.1 \%)$ & $1(4.5 \%)$ & $1(0.8 \%)$ & $7(13.2 \%)$ & $4(5.9 \%)$ & \\
\hline
\end{tabular}

Seventy women (78.6\%) with chronic hypertension received LDA $(25.7 \% 75 \mathrm{mg} ; 37.1 \% 100 \mathrm{mg}$; $37.1 \% 150 \mathrm{mg}$ ), starting at first trimester, in 30 cases $(42.9 \%)$ due to a pathologic first trimester screening for preeclampsia (Table 1). From the beginning of pregnancy, 40 women $(90.9 \%)$ with APS/SLE received LDA (10\% $75 \mathrm{mg} ; 57.5 \% 100 \mathrm{mg} ; 32.5 \%$ 150mg). Women (84.1\%) with APS/SLE received low-molecular-weight heparin (LMWH, enoxaparin) from diagnosis of pregnancy until 6 weeks postpartum (Table 1). Receiving LMWH from the beginning of pregnancy until 6 weeks postpartum were 21 women with APS/SLE (95.5\%), and 10 women (45.5\%) received LDA (10\% $75 \mathrm{mg} ; 50 \% 100 \mathrm{mg}$; $40 \% 150 \mathrm{mg}$ ), starting at first trimester, in two cases (20\%) due to a pathologic first trimester screening for preeclampsia. One hundred and ten $(93.2 \%)$ women with a history of preeclampsia received LDA (11\% $75 \mathrm{mg} ; 54.7 \% 100 \mathrm{mg} ; 31.9 \% 150 \mathrm{mg}$ ) from the beginning of pregnancy (Table 1). After a few weeks, eight women stopped taking LDA self-reliant. Fifty-one women (96.2\%) with a pathologic first trimester screening for preeclampsia received LDA (25.7\% $75 \mathrm{mg} ; 50.4 \% 100 \mathrm{mg} ; 23.9 \% 150 \mathrm{mg})$. None of the women of the control group received LDA nor LMWH. Despite treatment with LDA, 22 women developed preeclampsia; only six of them developed preeclampsia before 34 weeks of gestation.

\subsection{Longitudinal Changes of Sflt-1/Plgf Ratio during Pregnancy in Women with Adverse Obstetric Outcome Compared to Women with Normal Pregnancies}

The sFlt-1/PIGF ratio was significantly higher in women with an adverse obstetric outcome compared to women with a normal pregnancy in all six study groups, starting between 20 and 24 weeks of gestation (Table 2). The sFlt-1/PlGF ratio increased with gestational age in both women with an adverse obstetric outcome and women with normal pregnancies, but to a much higher extent in women with adverse obstetric outcome $(p<0.001)$ (Figure 1, Tables 2 and 3). 
Table 2. Longitudinal changes of sFlt-1/PlGF ratio during pregnancy in women with adverse obstetric outcome compared to women with normal pregnancies.

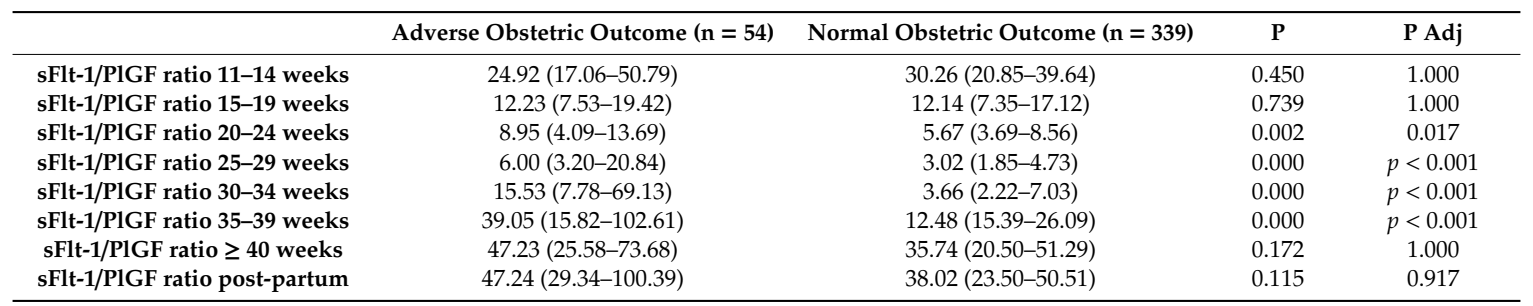

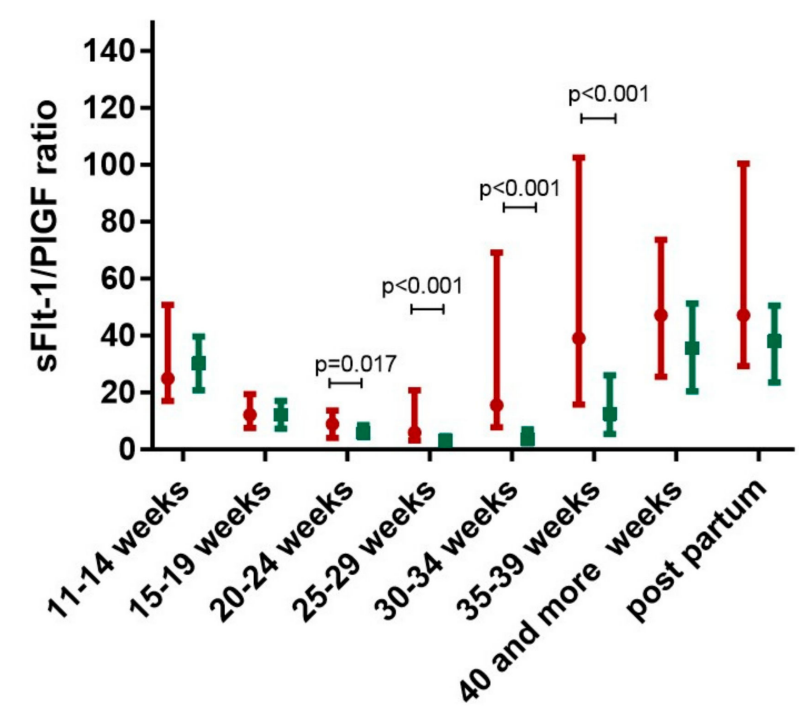

\section{- adverse obstetric outcome \\ - normal obstetric outcome}

Figure 1. Longitudinal changes of soluble FMS-like Tyrosine Kinase 1 (sFlt-1)/placental growth factor (PIGF) ratio during pregnancy in women with adverse obstetric outcome compared to women with normal pregnancies.

Table 3. Longitudinal changes of sFlt-1/PlGF ratio during pregnancy.

\begin{tabular}{cccc}
\hline Parameter & \multicolumn{3}{c}{ sFlt/PIGF Ratio } \\
\hline Fixed Part & Estimate & SE & P \\
\hline Intercept & 9.51 & 1.81 & $p<0.001$ \\
outcome & 3.14 & 4.91 & 0.52 \\
visits & 1.65 & 0.36 & $p<0.001$ \\
outcome*visits $^{*}$ & 5.89 & 1.04 & $p<0.001$ \\
\hline
\end{tabular}

\subsection{Effect of Lda on Sflt-1/Plgf Ratio in Women with and without Adverse Obstetric Outcome}

There was no effect of LDA on sFlt-1/PlGF ratio in women with and without adverse obstetric outcome (Table 4).

Table 4. Effect of low-dose aspirin (LDA) on sFlt-1/PlGF ratio in women with adverse obstetric outcome.

\begin{tabular}{ccccc}
\hline & Yes $(\mathbf{n}=\mathbf{4 4})$ & No $(\mathbf{n}=\mathbf{1 0})$ & P & P Adj \\
\hline sFlt-1/PIGF ratio 11-14 weeks & $25.46(18.94-49.49)$ & $17.23(15.24-84.12)$ & 0.484 & 1.000 \\
sFlt-1/PIGF ratio 15-19 weeks & $11.80(7.39-21.31)$ & $15.45(15.45-15.45)$ & n.a. & n.a. \\
sFlt-1/PIGF ratio 20-24 weeks & $8.22(3.90-12.22)$ & $11.95(8.06-23.31)$ & 0.079 & 0.630 \\
sFlt-1/PIGF ratio 25-29 weeks & $5.52(3.05-19.96)$ & $16.43(8.53-25.73)$ & 0.171 & 1.000 \\
sFlt-1/PIGF ratio 30-34 weeks & $14.39(7.16-106.19)$ & $22.54(8.16-59.23)$ & 0.902 & 1.000 \\
sFlt-1/PIGF ratio 35-39 weeks & $37.49(16.67-102.25)$ & $41.40(12.53-116.06)$ & 0.859 & 1.000 \\
sFlt-1/PIGF ratio $\geq$ 40 weeks & $43.16(17.05-74.10)$ & $47.24(33.99-158.25)$ & 0.558 & 1.000 \\
sFlt-1/PIGF ratio post-partum & $56.42(29.34-100.39)$ & $46.41(28.19-194.60)$ & 0.806 & 1.000 \\
\hline
\end{tabular}


Additionally, there was no effect of LDA on sFlt-1/PIGF ratio, regardless obstetric outcome (Table 5).

Table 5. Longitudinal changes of sFlt-1/PlGF ratio during pregnancy.

\begin{tabular}{cccc}
\hline Parameter & \multicolumn{3}{c}{ sFlt/PIGF Ratio } \\
\hline Fixed Part & Estimate & SE & P \\
\hline Intercept & 12.12 & 3.13 & 0.000 \\
ASS & -1.99 & 3.79 & 0.599 \\
visits & 2.50 & 0.60 & $p<0.001$ \\
ASS*visits & -0.39 & 0.74 & 0.593 \\
\hline SE=standard error & & & \\
\hline
\end{tabular}

\subsection{Effect of Lda on Sflt-1/Plgf Ratio in Different Study Groups}

LDA treatment affected the sFlt-1/PIGF ratio in women with a pathologic first trimester screening for preeclampsia (group 6) in a dose-dependent manner (Figure 2). The use of LDA showed a trend towards an improved sFlt-1/PlGF ratio in women with preeclampsia in a previous pregnancy (group $4)$, but results did not reach significance.

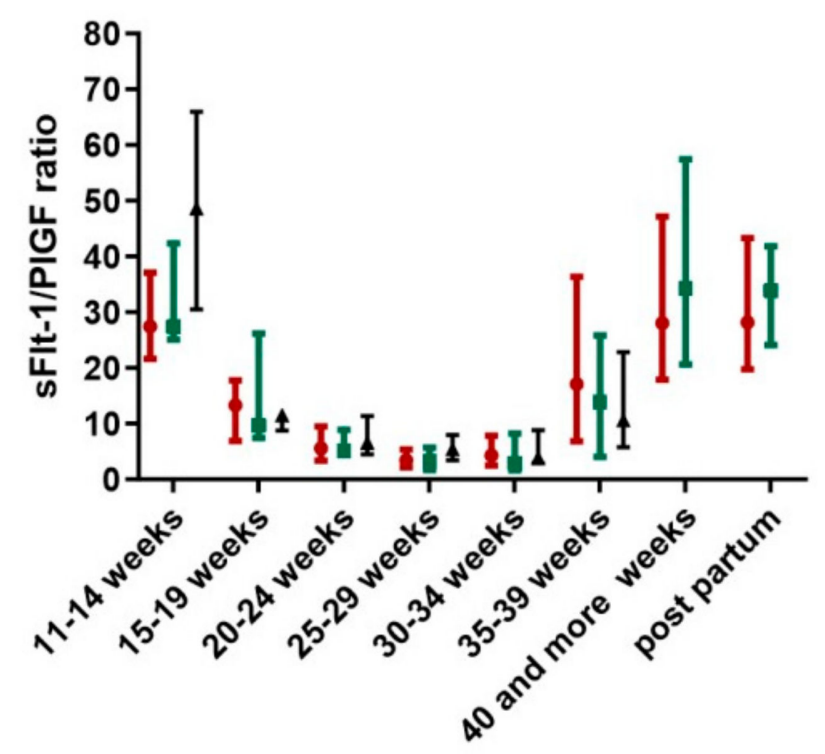

$\triangle \quad \mathrm{LDA}=0 \mathrm{mg}$

- $\quad$ LDA $\leqslant 100 \mathrm{mg}$

- $L D A \geqslant 150 \mathrm{mg}$

Figure 2. Effect of LDA on sFlt-1/PlGF ratio in women with a pathologic first trimester screening for preeclampsia.

There was no effect of LDA on sFlt-1/PlGF ratio in women with chronic hypertension (group 1), in women with APS/SLE (group 2), in women with thrombophilia (group 3) and controls (group 5) (Table 6). 
Table 6. Longitudinal changes of sFlt-1/PlGF ratio during pregnancy.

\begin{tabular}{|c|c|c|c|}
\hline \multirow{2}{*}{$\begin{array}{l}\text { Parameter } \\
\text { Fixed Part }\end{array}$} & \multicolumn{3}{|c|}{ sFlt/PlGF Ratio } \\
\hline & Estimate & SE & $\mathbf{P}$ \\
\hline \multicolumn{4}{|c|}{ chronic hypertension } \\
\hline Intercept & 2.00 & 10.23 & 0.845 \\
\hline LDA & 3.20 & 11.36 & 0.778 \\
\hline visits & 3.73 & 2.05 & 0.070 \\
\hline LDA *visits & -0.17 & 2.29 & 0.940 \\
\hline \multicolumn{4}{|l|}{ APS/SLE } \\
\hline Intercept & 7.03 & 12.22 & 0.566 \\
\hline LDA & 5.83 & 12.75 & 0.648 \\
\hline visits & 1.00 & 2.35 & 0.672 \\
\hline LDA *visits & -0.26 & 2.46 & 0.915 \\
\hline \multicolumn{4}{|l|}{ thrombophilia } \\
\hline Intercept & 26.80 & 16.99 & 0.130 \\
\hline LDA & -12.65 & 25.34 & 0.623 \\
\hline visits & 1.93 & 1.37 & 0.164 \\
\hline LDA $^{*}$ visits & -2.05 & 1.95 & 0.297 \\
\hline \multicolumn{4}{|c|}{ history of adverse obstetric outcome } \\
\hline Intercept & 11.22 & 12.10 & 0.354 \\
\hline LDA & 2.82 & 12.55 & 0.822 \\
\hline visits & 3.14 & 2.08 & 0.132 \\
\hline LDA*visits & -1.97 & 2.18 & 0.368 \\
\hline \multicolumn{4}{|c|}{ pathologic first trimester screening } \\
\hline Intercept & 42.79 & 18.94 & 0.025 \\
\hline LDA & -39.47 & 19.66 & 0.046 \\
\hline visits & -6.73 & 4.25 & 0.115 \\
\hline LDA*visits $^{*}$ & 10.78 & 4.36 & 0.015 \\
\hline $\mathrm{SE}=$ standard err & & & \\
\hline
\end{tabular}

\section{Discussion}

The main finding of this prospective longitudinal study showed that the use of LDA affected the sFlt-1/PlGF ratio in women with a pathologic first trimester screening for preeclampsia in a dose-dependent manner and showed a trend towards an improved sFlt-1/PlGF ratio in women with preeclampsia in a previous pregnancy.

Recent studies have suggested that aspirin and aspirin-like compounds have a variety of actions in addition to their well-studied ability to inhibit cyclooxygenases. Some of these effects may act via different pathways from those that enhance the trophoblast [26].

The effect of aspirin on angiogenic factors, such as sFlt- 1 and PIGF is the subject of ongoing interest and has been examined in several in vitro studies [27-31].

$\mathrm{Li}$ et al. reported that aspirin seems to be able to block the production of sFlt1 in the placenta in a dose-dependent manner, suggesting that aspirin exerts its therapeutic effects via cyclooxygenase-1 inhibition [27]. However, $\mathrm{Xu}$ et al. demonstrated in their in vitro study that aspirin improves trophoblast cell integration by inhibiting the effect of TNF-alpha via PGI2, but without affecting VEGF, PIGF and sFlt-1 [28].

Panagodage et al. revealed that aspirin modulates the production of cytokines and improves trophoblast function; additionally, it increases the secretion of PlGF from the trophoblast [29].

Su et al. investigated the effect of aspirin on trophoblast cell function and its effect on sFlt-1. The authors demonstrated that aspirin enhances cell invasiveness and inhibits sFlt-1 production in trophoblasts. Moreover, sFlt-1 itself also inhibits trophoblast invasion [30]. 
However, the underlying pathophysiology of how aspirin prevents preeclampsia is not fully understood. The interaction of aspirin, preeclampsia and angiogenic factors such as sFlt- 1 and PlGF, the role with the disease process and if aspirin has, if any, an effect on angiogenic factors is still unknown.

Mone et al. aimed to determine the impact of low-dose aspirin in low-risk pregnancies on several biomarkers such as PAPP-A and PIGF as well as on maternal blood pressure, fetal growth parameters, and histological findings of the placenta [31]. The authors could not find any significant impact of low-dose aspirin on these parameters. However, only $75 \mathrm{mg}$ of aspirin was prescribed; it might be speculated that the results may be different with higher dosages.

According to our results, LDA seems to have an effect on the sFlt-1/PlGF ratio women with a pathologic first trimester screening for preeclampsia.

Murtoniemi et al. aimed to study the effect of LDA $100 \mathrm{mg}$ on maternal PlGF concentrations in women with clinical risk factors for preeclampsia and of low-risk women and revealed an association of LDA and a higher increase in serum PIGF concentration in women at high risk for preeclampsia during pregnancy [32]. Our results confirm these findings and even show a dose-dependent effect of aspirin with the most prominent effects at a dosage of $150 \mathrm{mg}$.

We were not able to detect the same effect in women with chronic hypertension, APS/SLE, thrombophilia, as well as in women with preeclampsia in a previous pregnancy; it might be speculated that the effectiveness of aspirin differs among various entities.

The sFlt-1/PIGF ratio was significantly higher in women with an adverse obstetric outcome compared to women with a normal pregnancy in high- and low-risk pregnancies and showed an increasing trend throughout gestation

Several studies already reported altered maternal concentrations of sFlt- 1 and PlGF before and at the onset of preeclampsia [33-41] and therefore have a high predictive value [42-50]. Our results strongly support these finding.

Khalil et al. investigated longitudinal changes of maternal serum concentrations of sFlt- 1 and PIGF in 243 women with a pathologic first trimester screening for preeclampsia [49]. The authors demonstrated a higher predictive value of repeated measurements of angiogenic factors compared to single measurements. However, they could not find any significant association of sFlt- 1 and PIGF-levels and several maternal characteristics such as history of preeclampsia or chronic hypertension. These findings are in line with our results, as we were not able to reveal any significant differences of the sFlt-1/PIGF ratio between women with chronic hypertension or a history of preeclampsia, as well as women with APS/SLE, thrombophilia, a pathologic first trimester screening for preeclampsia and controls.

Powers et al. aimed to reveal differences of angiogenic factors in 993 high-risk pregnancies throughout gestation, consisting of women with pre-existing diabetes, chronic hypertension, and preeclampsia in a previous pregnancy as well as multi-fetal pregnancies. The authors reported significantly higher levels of sFlt-1 and endoglin and significantly lower levels of PIGF in women who developed preeclampsia but also noted that these changes are similar to those in low-risk pregnant women. Additionally, they could not find any differences in concentrations of sFlt- 1 and PlGF between women with or without aspirin prophylaxis treatment, suggesting that aspirin does not have a significant effect on the concentration of angiogenic factors [50].

\section{Conclusions}

We were able to reveal an association of LDA and sFlt-1/PlGF ratio in women with a pathologic first trimester screening for preeclampsia and showed a dose-dependent effect of aspirin with the most prominent effects at a dosage of $150 \mathrm{mg}$.

However, larger sample sizes are needed for a distinct interpretation and to confirm a specific trend of the statistical analysis. 
Additionally, we demonstrated that the sFlt-1/PIGF ratio was significantly higher in women with an adverse obstetric outcome compared to women with a normal pregnancy in high- and low- risk pregnancies and showed an increasing trend throughout gestation.

The strengths of the present study are the prospective design of the study, as well as the longitudinal measurements of angiogenic factors every 4 weeks, the comparison of angiogenic factors in women with different risk factors for the development of preeclampsia, as well as the determination of an effect of LDA on angiogenic factors.

A limitation of the study is the rather small sample size of individual study groups.

Author Contributions: Conceptualization, K.M.P., J.M., I.C.L., D.U., B.C., B.O.P., and M.C.Z.; data curation, C.S., J.M., and I.C.L.; formal analysis, K.E. and S.T.; funding acquisition, M.C.Z.; investigation, C.S., J.M., D.U., and M.C.Z.; methodology, B.O.P.; project administration, K.M.P., B.O.P., U.L., and M.C.Z.; resources, U.L. and M.C.Z.; software, B.O.P.; supervision, B.O.P., U.L., and M.C.Z.; writing-original draft, K.M.P. and V.K.K.; writing-review and editing, C.S., J.M., I.C.L., D.U., B.C., B.O.P., U.L., and M.C.Z.

Funding: This study was funded by a grant from the Jubilee Fund of the Austrian National Bank (OeNB grant No 16138).

Acknowledgments: The authors would like to acknowledge Roche Diagnostics for providing the sFlt1-PlGF assays. We thank our patients for their contribution and our colleagues, especially our study nurses Bettina Amtmann and Petra Winkler for continuing support.

Conflicts of Interest: The authors declare no conflict of interest.

\section{References}

1. American College of Obstetricians and Gynecologists. Hypertension in pregnancy. Report of the American College of Obstetricians and Gynecologists' task force on hypertension in pregnancy. Obstet. Gynecol. 2013, 122, 1122-1131.

2. Tranquilli, A.L.; Dekker, G.; Magee, L.; Roberts, J.; Sibai, B.M.; Steyn, W.; Zeeman, G.G.; Brown, M.A. The classification, diagnosis and management of the hypertensive disorders of pregnancy: A revised statement from the ISSHP. Pregnancy Hypertens. 2014, 4, 97-104. [CrossRef] [PubMed]

3. Sibai, B.M.; Lindheimer, M.; Hauth, J.; Caritis, S.; VanDorsten, P.; Klebanoff, M.; MacPherson, C.; Landon, M.; Miodovnik, M.; Paul, R.; et al. National Institute of Child Health and Human Development Network of Maternal-Fetal Medicine Units. Risk factors for preeclampsia, abruptio placentae, and adverse neonatal outcomes among women with chronic hypertension. N. Engl. J. Med. 1998, 339, 667-671. [CrossRef] [PubMed]

4. $\quad$ Caritis, S.; Sibai, B.; Hauth, J.; Lindheimer, M.; VanDorsten, P.; Klebanoff, M.; Thom, E.; Landon, M.; Paul, R.; Miodovnik, M.; et al. National Institute of Child Health and Human Development Network of Maternal-Fetal Medicine Units. Predictors of pre-eclampsia in women at high risk. Am. J. Obstet. Gynecol. 1998, 179, $946-951$. [CrossRef]

5. Simard, J.F.; Arkema, E.V.; Nguyen, C.; Svenungsson, E.; Wikström, A.K.; Palmsten, K.; Salmon, J.E. Early-onset Preeclampsia in Lupus Pregnancy. Paediatr. Perinat. Epidemiol. 2017, 31, 29-36. [CrossRef] [PubMed]

6. Chakravarty, E.F.; Colon, I.; Langen, E.S.; Nix, D.A.; El-Sayed, Y.Y.; Genovese, M.C.; Druzin, M.L. Factors that predict prematurity and preeclampsia in pregnancies that are complicated by systemic lupus erythematosus. Am. J. Obstet. Gynecol. 2005, 192, 1897-1904. [CrossRef] [PubMed]

7. Chakravarty, E.F.; Nelson, L.; Krishnan, E. Obstetric hospitalizations in the United States for women with systemic lupus erythematosus and rheumatoid arthritis. Arthritis Rheum. 2006, 54, 899-907. [CrossRef]

8. Petri, M. Hopkins Lupus Pregnancy center: 1987-1996. Rheum. Dis. Clin. N. Am. 1997, 23, 1-13. [CrossRef]

9. Clark, E.A.; Silver, R.M.; Branch, D.W. Do antiphospholipid antibodies cause preeclampsia and HELLP syndrome? Curr. Rheumatol. Rep. 2007, 9, 219-225. [CrossRef]

10. Gibbins, K.J.; Ware Branch, D. Pre-eclampsia as a manifestation of antiphospholipid syndrome: Assessing the current status. Lupus 2014, 23, 1229-1231. [CrossRef]

11. Steegers, E.A.; von Dadelszen, P.; Duvekot, J.J.; Pijnenborg, R. Pre-eclampsia. Lancet 2010, 376, 631-644. [CrossRef]

12. Kupferminc, M.J. Thrombophilia and pregnancy. Reprod. Biol. Endocrinol. 2003, 1, 111. [CrossRef] [PubMed] 
13. Roberts, J.M.; Hubel, C.A. The two stage model of preeclampsia: Variations on the theme. Placenta 2009, 30, 32-37. [CrossRef] [PubMed]

14. Young, B.C.; Levine, R.J.; Karumanchi, S.A. Pathogenesis of preeclampsia. Annu. Rev. Pathol. 2010, 5, $173-192$. [CrossRef] [PubMed]

15. Saito, S.; Sakai, M. Th1/Th2 balance in preeclampsia. J. Reprod. Immunol. 2003, 59, 161-173. [CrossRef]

16. Redman, C.W.; Sargent, I.L. Latest advances in understanding preeclampsia. Science 2005, 308, $1592-1594$. [CrossRef]

17. Askie, L.M.; Duley, L.; Henderson-Smart, D.J.; Stewart, L.A.; PARIS Collaborative Group. Antiplatelet agents for prevention of preeclampsia: A meta-analysis of individual patient date. Lancet 2007, 369, 1791-1798. [CrossRef]

18. Roberge, S.; Villa, P.; Nicolaides, K.; Giguère, Y.; Vainio, M.; Bakthi, A.; Ebrashy, A.; Bujold, E. Early Administration of Low-Dose Aspirin for the Prevention of Preterm and Term Preeclampsia: A Systematic Review and Meta-Analysis. Fetal Diagn. Ther. 2012, 31, 141-146. [CrossRef]

19. Roberge, S.; Bujold, E.; Nicolaides, K.H. Aspirin for the prevention of preterm and term preeclampsia: Systematic review and metaanalysis. Am. J. Obstet. Gynecol. 2018, 218, 287-293. [CrossRef]

20. Villa, P.M.; Kajantie, E.; Räikkönen, K.; Pesonen, A.-K.; Hämäläinen, E.; Vainio, M.; Taipale, P.; Laivuori, H.; PREDO Study Group. Aspirin in the prevention of pre-eclampsia in high-risk women: A randomised placebo-controlled PREDO Trial and a meta-analysis of randomised trials. BJOG 2013, 120, 64-74. [CrossRef]

21. Rolnik, D.L.; Wright, D.; Poon, L.C.; O'Gorman, N.; Syngelaki, A.; de Paco Matallana, C.; Akolekar, R.; Cicero, S.; Janga, D.; Singh, M.; et al. Aspirin versus Placebo in Pregnancies at High Risk for Preterm Preeclampsia. N. Engl. J. Med. 2017, 377, 613-622. [CrossRef] [PubMed]

22. Tong, S.; Mol, B.W.; Walker, S.P. Preventing preeclampsia with aspirin: Does dose or timing matter? Am. J. Obstet. Gynecol. 2017, 216, 95-97. [CrossRef] [PubMed]

23. Miyakis, S.; Lockshin, M.D.; Atsumi, T.; Branch, D.W.; Brey, R.L.; Cervera, R.; Derksen, R.H.; DE Groot, P.G.; Koike, T.; Meroni, P.L.; et al. International consensus statement on an update of the classification criteria for definite antiphospholipide syndrome (APS). J. Thromb. Haemost. 2006, 4, 295-306. [CrossRef] [PubMed]

24. Hochberg, M.C. Updating the American College of Rheumatology revised criteria for the classification of systemic lupus erythematosus. Arthitis Rheum. 1997, 40, 1725. [CrossRef] [PubMed]

25. ACOG Committee on Practice Bulletins-Obstetrics. ACOG practice bulletin. Diagnosis and management of preeclampsia and eclampsia. Obstet. Gynecol. 2002, 99, 159-167.

26. Amin, A.R.; Attur, M.G.; Pillinger, M.; Abramson, S.B. The pleiotropic functions of aspirin: Mechanisms of action. Cell. Mol. Life Sci. 1999, 56, 305-312. [CrossRef] [PubMed]

27. Li, C.; Raikwar, N.S.; Santillan, M.K.; Santillan, D.A.; Thomas, C.P. Aspirin inhibits expression of sFLT1 from human cytotrophoblasts induced by hypoxia, via cyclo-oxygenase 1. Placenta 2015, 36, 446-453. [CrossRef] [PubMed]

28. Xu, B.; Shanmugalingam, R.; Chau, K.; Pears, S.; Hennessy, A.; Makris, A. The effect of acetyl salicylic acid (Aspirin) on trophoblast-endothelial interaction in vitro. J. Reprod. Immunol. 2017, 124, 54-61. [CrossRef] [PubMed]

29. Panagodage, S.; Yong, H.E.; Da Silva Costa, F.; Borg, A.J.; Kalionis, B.; Brennecke, S.P.; Murthi, P. Low-Dose Acetylsalicylic Acid Treatment Modulates the Production of Cytokines and Improves Trophoblast Function in an in-Vitro Model of Early-Onset Preeclampsia. Am. J. Pathol. 2016, 186, 3217-3224. [CrossRef] [PubMed]

30. Su, M.T.; Wang, C.Y.; Tsai, P.Y.; Chen, T.Y.; Tsai, H.L.; Kuo, P.L. Aspirin enhances trophoblast invasion and represses soluble fms-like tyrosine kinase 1 production: A putative mechanism for preventing preeclampsia. J. Hypertens. 2019. [CrossRef] [PubMed]

31. Mone, F.; Mulcahy, C.; McParland, P.; Downey, P.; Culliton, M.; Maguire, O.C.; Mooney, E.E.; Clarke, P.; Fitzgerald, D.; Tully, E.; et al. Evaluation of the Effect of Low-Dose Aspirin on Biochemical and Biophysical Biomarkers for Placental Disease in Low-Risk Pregnancy: Secondary Analysis of a Multicenter RCT. Am. J. Perinatol. 2019. [CrossRef] [PubMed]

32. Murtoniemi, K.; Vahlberg, T.; Hämäläinen, E.; Kajantie, E.; Pesonen, A.K.; Räikkönen, K.; Taipale, P.; Villa, P.M.; Laivuori, H. The effect of low-dose aspirin on serum placental growth factor levels in a high-risk PREDO cohort. Pregnancy Hypertens. 2018, 13, 51-57. [CrossRef] [PubMed] 
33. Maynard, S.E.; Min, J.Y.; Merchan, J.; Lim, K.-H.; Li, J.; Mondal, S.; Libermann, T.A.; Morgan, J.P.; Sellke, F.W.; Stillman, I.E.; et al. Excess placental soluble fms-like tyrosine kinase 1 (sFlt1) may contribute to endothelial dysfunction, hypertension, and proteinuria in preeclampsia. J. Clin. Investig. 2003, 111, 649-658. [CrossRef] [PubMed]

34. Levine, R.J.; Maynard, S.E.; Qian, C.; Lim, K.H.; England, L.J.; Yu, K.F.; Schisterman, E.F.; Thadhani, R.; Sachs, B.P.; Epstein, F.H.; et al. Circulating angiogenic factors and the risk of preeclampsia. N. Engl. J. Med. 2004, 350, 672-683. [CrossRef]

35. Verlohren, S.; Herraiz, I.; Lapaire, O.; Schlembach, D.; Moertl, M.; Zeisler, H.; Calda, P.; Holzgreve, W.; Galindo, A.; Engels, T.; et al. The sFlt-1/PIGF ratio in different types of hypertensive pregnancy disorders and its prognostic potential in preeclamptic patients. Am. J. Obstet. Gynecol. 2012, 206, 58.e1-58.e8. [CrossRef] [PubMed]

36. Rana, S.; Powe, C.E.; Salahuddin, S.; Verlohren, S.; Perschel, F.H.; Levine, R.J.; Lim, K.H.; Wenger, J.B.; Thadhani, R.; Karumanchi, S.A. Angiogenic factors and the risk of adverse outcomes in women with suspected preeclampsia. Circulation 2012, 125, 911-919. [CrossRef]

37. Chaiworapongsa, T.; Romero, R.; Savasan, Z.A.; Kusanovic, J.P.; Ogge, G.; Soto, E.; Dong, Z.; Tarca, A.; Gaurav, B.; Hassan, S.S. Maternal plasma concentrations of angiogenic/anti-angiogenic factors are of prognostic value in patients presenting to the obstetrical triage area with the suspicion of preeclampsia. J. Matern. Fetal Neonatal. Med. 2011, 24, 1187-1207. [CrossRef]

38. Sibiude, J.; Guibourdenche, J.; Dionne, M.D.; Le Ray, C.; Anselem, O.; Serreau, R.; Goffinet, F.; Tsatsaris, V. Placental growth factor for the prediction of adverse outcomes in patients with suspected preeclampsia or intrauterine growth restriction. PLoS ONE 2012, 7, e50208. [CrossRef]

39. Chappell, L.C.; Duckworth, S.; Seed, P.T.; Griffin, M.; Myers, J.; Mackillop, L.; Simpson, N.; Waugh, J.; Anumba, D.; Kenny, L.C.; et al. Diagnostic accuracy of placental growth factor in women with suspected preeclampsia: A prospective multicenter study. Circulation 2013, 128, 2121-2131. [CrossRef]

40. Ohkuchi, A.; Hirashima, C.; Takahashi, K.; Suzuki, H.; Matsubara, S.; Suzuki, M. Onset threshold of the plasma levels of soluble fms-like tyrosine kinase 1/placental growth factor ratio for predicting the imminent onset of preeclampsia within 4 weeks after blood sampling at 19-31 weeks of gestation. Hypertens. Res. 2013, 36, 1073-1080. [CrossRef]

41. Akolekar, R.; Zaragoza, E.; Poon, L.C.; Pepes, S.; Nicolaides, K.H. Maternal serum placental growth factor at $11+0$ to $13+6$ weeks of gestation in the prediction of pre-eclampsia. Ultrasound Obstet. Gynecol. 2008, 32, 732-739. [CrossRef] [PubMed]

42. Poon, L.C.; Nicolaides, K.H. Early Prediction of Preeclampsia. Obstet. Gynecol. Int. 2014, 2014. [CrossRef] [PubMed]

43. Romero, R.; Nien, J.K.; Espinoza, J.; Todem, D.; Fu, W.; Chung, H.; Kusanovic, J.P.; Gotsch, F.; Erez, O.; Mazaki-Tovi, S.; et al. A longitudinal study of angiogenic (placental growth factor) and anti-angiogenic (soluble endoglin and soluble vascular endothelial growth factor receptor-1) factors in normal pregnancy and patients destined to develop preeclampsia and deliver a small for gestational age neonate. J. Matern. Fetal Neonatal. Med. 2008, 21, 9-23. [PubMed]

44. Moore Simas, T.A.; Crawford, S.L.; Bathgate, S.; Yan, J.; Robidoux, L.; Moore, M.; Maynard, S.E. Angiogenic biomarkers for prediction of early preeclampsia onset in high-risk women. J. Matern. Fetal Neonatal. Med. 2014, 27, 1038-1048. [CrossRef] [PubMed]

45. Moore Simas, T.A.; Crawford, S.L.; Solitro, M.J.; Frost, S.C.; Meyer, B.A.; Maynard, S.E. Angiogenic factors for the prediction of preeclampsia in high-risk women. Am. J. Obstet. Gynecol. 2007, 197, 244.e1-244.e8. [CrossRef] [PubMed]

46. Palomaki, G.E.; Haddow, J.E.; Haddow, H.R.; Salahuddin, S.; Geahchan, C.; Cerdeira, A.S.; Verlohren, S.; Perschel, F.H.; Horowitz, G.; Thadhani, R.; et al. Modeling risk for severe adverse outcomes using angiogenic factor measurements in women with suspected preterm preeclampsia. Prenat. Diagn. 2015, 35, 386-393.

47. Maynard, S.E.; Crawford, S.L.; Bathgate, S. Gestational angiogenic biomarker patterns in high risk preeclampsia groups. Am. J. Obstet. Gynecol. 2013, 209, 53.e1-53.e9.

48. Flint, E.J.; Cerdeira, A.S.; Redman, C.W.; Vatish, M. The role of angiogenic factors in the management of preeclampsia. Acta Obstet. Gynecol. Scand. 2019, 98, 700-707. [CrossRef] [PubMed] 
49. Khalil, A.; Maiz, N.; Garcia-Mandujano, R.; Penco, J.M.; Nicolaides, K.H. Longitudinal changes in maternal serum placental growth factor and soluble fms-like tyrosine kinase-1 in women at increased risk of pre-eclampsia. Ultrasound Obstet. Gynecol. 2016, 47, 324-331. [CrossRef]

50. Powers, R.W.; Jeyabalan, A.; Clifton, R.G.; Van Dorsten, P.; Hauth, J.C.; Klebanoff, M.A.; Lindheimer, M.D.; Sibai, B.; Landon, M.; Miodovnik, M.; et al. Soluble fms-Like tyrosine kinase 1 (sFlt1), endoglin and placental growth factor (PIGF) in preeclampsia among high risk pregnancies. PLoS ONE 2010, 5, e13263. [CrossRef]

(C) 2019 by the authors. Licensee MDPI, Basel, Switzerland. This article is an open access article distributed under the terms and conditions of the Creative Commons Attribution (CC BY) license (http://creativecommons.org/licenses/by/4.0/). 